\title{
ATEÍSMOS NO BRASIL: APRESENTANDO A OBRA O ATEÍSMO NO BRASIL
} (2020)

\section{Atheisms in Brazil: introducing the book O Ateísmo no Brasil (2020)}

\author{
Jônatas Ferreira de Lima Souza. ${ }^{1}$
}

\section{RESUMO}

Neste artigo temos por objetivo principal apresentar tópicos da obra O Ateísmo no Brasil: os sentidos da descrença nos séculos XX e XXI, de Ricardo Oliveira da Silva, historiador e professor da UFMS (campus de Nova Andradina). Os tópicos que selecionamos para apresentar e comentar foram: "As definições de ateísmo" (2020, p. 14-17); "O ateísmo na historiografia brasileira" (p. 17-29); "O ateísmo materialista na obra de intelectuais comunistas brasileiros" (p. 129-138); "A criação da Revista Ateísta" (p. 198-218); e "Ateísmo e feminismo" (p. 215218). Como se pode notar, as discussões desta produção perpassam por definições de ateísmo; pela construção historiográfica desse ateísmo; pela chegada desse pensamento ateísta no Brasil; como as pesquisas nacionais estão lidando com essa temática do ateísmo; o movimento ateísta organizado e a criação de meios de divulgação, como revistas e sites; a questão feminina na educação científica e no ateísmo. Para cada um desses temas, criamos tópicos próprios, que serão comentados em nossas considerações no final deste artigo.

Palavras-chave: Ateísmo; Historiografia; Comunismo; Ciberateísmo; Feminismo.

\section{ABSTRACT}

The main objective of this work is to present topics from the book O Ateísmo no Brasil: os sentidos da descrença nos séculos XX e XXI, by Ricardo Oliveira da Silva, historian and professor at the Universidade Federal do Mato Grosso do Sul (Nova Andradina campus). The topics in this book that we selected to present and comment on are: "As definições de ateísmo" (2020, p. 14-17); "O ateísmo na historiografia brasileira" (p. 17-29); "O ateísmo materialista na obra de intelectuais comunistas brasileiros" (p. 129-138); "A criação da Revista Ateísta" (p. 198-218); e "Ateísmo e feminismo" (p. 215-218). In this sense, the discussions in this work go through definitions of atheism; by the historiographical construction of this atheism; by the arrival of this atheistic thought in Brazil; how Brazilian research is proceeding with this theme of atheism; about the organized atheist movement and the creation of means of dissemination, such as magazines and websites; the female issue in scientific education and atheism. For each of these themes, we divide them into specific topics, and we comment on them in our final remarks.

Keywords: Atheism; Historiography; Communism; Cyberatheism; Feminism.

\footnotetext{
${ }^{1}$ Mestre em Letras Clássicas (2019), Linha Interdisciplinar, pela Universidade Federal do Rio de Janeiro (UFRJ). Graduado em História Bacharelado (2014) e Licenciatura (2012), pela Universidade Federal do Rio Grande do Norte (UFRN). Técnico em Controle Ambiental (2007), pelo IFRN (antigo CEFET-RN). Atualmente, é graduando em Letras Português-Hebraico, pela Faculdade de Letras da Universidade Federal do Rio de Janeiro (FL-UFRJ). REVISTA RELEGENS THRÉSKEIA - 2021 - UFPR
} 


\section{Introdução}

A obra O Ateísmo no Brasil: os sentidos da descrença nos séculos XX e XXI, de 2020, de Ricardo Oliveira da Silva, historiador e professor da UFMS (campus de Nova Andradina), não só traz ao cenário nacional uma discussão historiográfica sobre o ateísmo, mas também a sua complexa construção indenitária, e, não menos importante, o seu paralelo, nas últimas décadas, com a luta pelas liberdades individuais e por um estado de fato laico de democracia plena. Em sua Introdução (p. 7-12), o autor mostra que, nas universidades brasileiras, o tema do ateísmo está presente em alguns estudos sobre religião. Entretanto, como tema em si, como objeto de pesquisa, fora pouco explorado, considerando, assim, uma real lacuna a ser trabalhada pela academia.

O livro foi pensado pelo autor durante sua experiência ao ministrar um curso sobre História do Ateísmo na UFMS. Uma proposta pioneira e inovadora que foi acatada pelo Colegiado do Curso de História em 2018 e aplicado ao público acadêmico em 2019. Entre 2018 e 2019 o autor também coordenou um projeto de pesquisa intitulado "Um mundo sem crença em Deus: um estudo sobre o ateísmo no anarquismo, comunismo e neoateísmo brasileiro (séculos $X X$ e XXI)", que, só pelo título, demonstra a influência direta no resultado final do livro.

A sua primeira edição foi publicada pela Paco Editorial no ano de 2020. Um ano atípico não só para o Brasil, mas para todos os povos do mundo. No caso brasileiro, com o acometimento da pandemia da COVID-19, que ainda persiste em 2021, observou-se que o discurso da religião se fez presente na voz dos governantes. Um discurso que tentava conciliar, no geral, a luta diária da ciência contra a pandemia e outras mazelas que acompanharam o estado de caos, com palavras de conforto, esperança e salvação típicas do âmbito religioso que mostra a força da religião na cultura brasileira. Em paralelo a esse discurso de conforto, instituições públicas de ensino sofreram com cortes de verbas que inviabilizaram diversas pesquisas e projetos. As instituições tiveram que sustentar o período letivo sob ensino remoto de aulas a distância. Não somente aulas, mas também eventos, congressos, simpósios, etc., todos foram organizados em plataformas de videoconferências.

Foi dentro desse cenário de dificuldades generalizas para educação, saúde, segurança, economia, etc., acompanhado desse fortalecimento do apreço governamental pelo discurso religioso, particularmente cristão, que a obra de Ricardo Oliveira da Silva sobre ateísmo chega ao público. Essa obra, como dito, não se trata de um trabalho que se limita ao campo das 
identidades, mas também lida com a história de uma cultura que se desenvolveu de forma plural no entorno dessa palavra, uma história de longa duração que remonta dos filósofos gregos aos nossos dias. Diante de tantas incertezas no cenário político, e com o recorrente descrédito da laicidade pelo próprio estado, a obra vem enfatizar, com pesquisa e documentação, a importância de um estado laico e democrático para a liberdade cidadã mediante direitos e deveres conquistados ao longo de anos de luta.

Com isso em vista, temos por objetivo principal, neste artigo, apresentar tópicos específicos dessa obra, a saber: “As definições de ateísmo" (2020, p. 14-17); “O ateísmo na historiografia brasileira" (p. 17-29); “O ateísmo materialista na obra de intelectuais comunistas brasileiros” (p. 129-138); “A criação da Revista Ateísta” (p. 198-218); e “Ateísmo e feminismo" (p. 215-218). Não se trata aqui de uma resenha em si, mas de um artigo que tem por intuito apresentar e enfatizar, a partir dessa seleção de tópicos da obra, discussões que perpassem por definições de ateísmo; pela construção historiográfica desse ateísmo; pela chegada desse pensamento ateísta no Brasil; como as pesquisas nacionais estão lidando com essa temática do ateísmo; o movimento ateísta organizado e a criação de meios de divulgação, como revistas e sites; além da questão feminina na educação científica e no ateísmo. Para cada um desses temas, tópicos próprios foram criados, estes que serão comentados em nossas considerações no final deste artigo.

\section{Ateísmo: definições}

Esse primeiro tema diz respeito ao tópico “As definições de ateísmo” nas páginas 1417, apresentadas por Ricardo Oliveira da Silva. Nessa seção o autor localiza trabalhos cujas pesquisas sobre ateísmo são mais proeminentes, particularmente produções em língua inglesa. Essa primeira apresentação se mostra mais normativa: o primeiro deles é Julian Baggini, filósofo britânico. Segundo Silva, para Baggini (2016), ateu é quem é descrente na existência de qualquer divindade. O segundo é Michael Martin (1932-2015), filósofo estadunidense, que, segundo Silva, a partir da palavra grega átheos, considera que ateu é quem não tem crença em divindades, mas não necessariamente entra no tema da existência ou não delas. A partir disso, mostra Silva, Martin (2010) subdividiu a sua definição em ateísmo negativo e ateísmo positivo. Esse ateísmo será negativo no sentido de negar a crença em seres divinos (todos eles); e esse ateísmo será positivo no sentido de negar a (ou ser positivo quanto a não) existência de seres divinos (todos eles). O terceiro é Paul Cliteur, político e filósofo holandês. Segundo Silva, a 
definição de Cliteur (2009) passa pela condição da negação do teísmo. Num primeiro momento, é a negação ou rejeição da crença das religiões baseadas na Bíblia (um teísmo). Em um segundo momento, é o afastamento e negação das discussões sobre a existência do deus das crenças bíblicas (outro teísmo). Mostra Silva que, no fim das contas, para Cliteur, ateu é aquele que escolhe essa alcunha para si, após estudo e investigação atenta e crítica das religiões.

O quarto é Stephen LeDrew, sociólogo canadense. Mostra Silva que LeDrew (2013) é menos normativo em sua pesquisa, por deixar claro a complexidade do tema e do conceito. Nesse sentido, segundo Silva, LeDrew vê esse ateísmo como oriundo de formações intelectuais decorrentes do século XVIII, que se desdobram em duas rotas no século XIX: a) ateísmo cientificista - baseado nos estudos de Auguste Comte (1798-1857), Charles Darwin (18091882) e Herbert Spencer (1820-1903) - de exaltação às ciências naturais, de negação da existência de divindades, da religião como não científica e supersticiosa; b) ateísmo humanista - baseado em Ludwig Feuerbach (1804-1872), Karl Marx (1818-1883), Friedrich Nietzsche (1844-1900) e Sigmund Freud (1856-1939) - de exaltação ao combate ou minimização das mazelas sociais, de compreender a religião como uma realidade social, uma realidade que sobrevive pela desigualdade - isto é, acredita que mais bem-estar na vida social, desmonta a sustentabilidade das religiões teístas, levando-as ao desaparecimento.

\section{Historiografia brasileira e o ateísmo}

O segundo tema diz respeito ao tópico “O ateísmo na historiografia brasileira”, entre as páginas 17-29, em que Ricardo Oliveira da Silva explora um pouco mais esse desenvolvimento intelectual do ateísmo que culminou numa espécie de tradição historiográfica - uma tradição particularmente europeia. Para isso, o autor apresenta essencialmente dois pesquisadores que revisaram essa tradição: Julian Baggini (2016) e James Thrower (19361999). Segundo Silva, em suma, essa historiografia remonta a uma experiência de naturalistas e filósofos na Grécia antiga, e a uma retomada iluminista no século XVIII. Essa historiografia perpassa séculos de propostas esparsas, de investigações de fenômenos naturais, de explicar o mundo derredor de forma racional, sistemática, de reduzir os mitos a fábulas, de questionar o poder dado à religião e a seus argumentos, da valorização da humanidade e de seu esforço, da valorização do estudo científico em prol de um avanço social como um todo - ou seja, como demonstra Silva, é uma "história das ideias ateístas no Ocidente". Além desses, Silva destaca 
as impressões gerais de George Minois, historiador francês. Segundo o autor, para Minois (2014), a história do ateísmo também é uma história da descrença e não só uma história de ideias, mas uma história de comportamentos, que podem ser conjecturados ou verificados desde os primórdios da humanidade.

Destaca Silva que o ateísmo pode não ser um fenômeno recente, mas as produções acadêmicas sobre ele são. E se são poucas e recentes, nesse âmbito estadunidense e europeu (século XX), o que dizer do cenário brasileiro? Segundo Silva, um dos principais motivos para se ter tão poucos estudos sobre ateísmo, é devido à imagem social negativa construída, no âmbito privado e público, sobre o considerado descrente, herege, sobre ausência de religião, sobre comunismo, sobre política de esquerda, sobre o ateu - uma imagem forjada segundo os anseios de uma sociedade guiada por religiões teístas (de interpretação bíblica). O Brasil não foge dessa lógica, uma vez que sua estrutura pública e privada foi regida pelo cristianismo por mais de 450 anos. Diante dessa evidência, mostra Silva (2020, p. 21) que "não é de estranhar que os historiadores tenham produzido inúmeros estudos da religião e das práticas religiosas $[\ldots]^{\prime \prime}$.

Por outro lado, o autor alerta sobre a presença do fenômeno intelectual ateísta ser muito recente no Brasil (século XXI). Em questão de identidade, por exemplo, os dados do censo do IBGE 2010 mostram a identificação de pouco mais de $8 \%$ dos cidadãos com o ateísmo, agnosticismo ou com nenhuma religião (pouco mais de 15 milhões de pessoas, na época). Nesse sentido, o Brasil segue como um dos países mais religiosos (teístas) do mundo. Para medir esse interesse pelo tema do ateísmo nas universidades, Silva investigou os resultados obtidos no catálogo de teses e dissertações da Capes até 2018. Ao digitar a palavra "ateísmo", ali identificou menos de 100 resultados e ao digitar "ateu", menos de 50. Entretanto, em boa parte desses trabalhos de pesquisa, nem "ateísmo" nem "ateu" eram os objetos de estudo. O ateísmo como objeto foi interesse maior nas áreas de ciências da religião, filosofia e teologia. $\mathrm{Na}$ área de história, o ateísmo aparece ainda mais raro.

Contudo, aqueles que se propuseram a investigar o tema do ateísmo, segundo Silva, seguiram por dois eixos: a) ateísmo no ocidente - uma visão mais ampla da presença de ateísmos no século XX-XXI na cultura Ocidental, principalmente analisando perspectivas de autores como Freud, Pierre Bayle (1647-1706), e temas em voga no século XXI, como o neoateísmo e questões sociopolíticas, que envolve nomes como Richard Dawkins, Sam Harris, Daniel Dennett e Christopher Hitchens (1949-2011); nesse eixo, o autor constatou que o interesse pelo ateísmo no Brasil passa pelo campo do estudo das religiões (como um estudo da 
não religião, ou da não crença) e pelo estudo de obras relevantes para se pensar ateísmos e a questão do neoateísmo (a análise de obras e seus autores). No eixo b) ateísmo no cenário brasileiro - que em particular não foi encontrado pelo autor na pesquisa feita no catálogo da Capes, mas por meio de buscas no Google. Dentre os temas estão: ateísmo e o positivismo no Brasil, a militância ateísta da associação $\mathrm{Atea}^{2}$ nas redes sociais e no âmbito judiciário, o problema do Estado laico e suas controvérsias atuais, ateísmo como "crença” individual ou militância política, redes sociais na Internet como espaços de fala dos ateus; no âmbito desse eixo, o autor considera que a Atea tem sido objeto de estudo nas universidades e que é provável que pesquisas sobre ateísmo surjam com maior frequência no Brasil, principalmente devido a militância do neoateísmo nas redes sociais na Internet.

\section{Intelectuais comunistas no Brasil}

Esse terceiro tema diz respeito ao tópico "O ateísmo materialista na obra de intelectuais comunistas brasileiros", entre as páginas 129-138. Nessa discussão Ricardo Oliveira da Silva destaca o conceito de ateísmo marxista, ou, ateísmo materialista, entre os intelectuais brasileiros. Em poucas palavras, ateísmo marxista ou materialista e humanismo são como sinônimos, pois em ambos os casos se valoriza o ser humano e seu potencial de trabalho criador e criativo. A base teórica desse ateísmo marxista vem do materialismo histórico e dialético de Marx e Engels (século XIX) - por mais que ambos não tenham enveredado como teóricos do ateísmo (no mais, críticos da religião). Esse fator teórico e conceitual do ateísmo materialista é explorado pelo autor no tópico "O ateísmo materialista na obra de Marx e Engels" (2020, p. 88-104).

No cenário nacional, Silva destaca a atividade do PCB (Partido Comunista Brasileiro), fundado no Rio de Janeiro no início do século XX. Entretanto, mostra o autor, que uma associação clara entre ser adepto do comunismo e ser ateu militante não é evidente na maior parte das expressões dos membros do partido, durante o século XX. Dentre esses membros, Silva destaca Octávio Brandão (1896-1980), anarquista alagoano, membro do PCB desde o ano de sua fundação em 1922. Em seu livro Silva destaca o artigo "O primado da natureza - ciência e filosofia”, publicado na Revista Brasiliense, em 1961. Nele, segundo o autor, Brandão exalta um mundo regido por uma perspectiva idealizada do marxismo-leninista, do materialismo dialético - uma sociedade em que as classes opressoras e exploradoras não são favorecidas.

\footnotetext{
${ }^{2}$ Associação Brasileira de Ateus e Agnósticos, criada em 2008. Seus principais representantes são Daniel Sottomaior, Alfredo Spínola e Mauricio Palazzuoli.
} REVISTA RELEGENS THRÉSKEIA - 2021 - UFPR 
Essa valorização da dialética marxista, para Brandão, de acordo com Silva, simboliza uma exaltação da natureza e dos movimentos constantes e de suas transformações e renovações - a natureza como eterna e que sempre existiu, existe e existirá, ou seja, não foi criada, mas passa por constantes transformações. Mostra Silva que, para Brandão, o ser humano é um ser especial que atua sobre a natureza por meio de ciência e tecnologia, sendo dotado de um cérebro que pensa, e que todo sobrenatural é uma ilusão, uma imaginação que é sustentada por interesses diversos e comumente opressores - a alma, portanto, é o cérebro e não um espírito imaterial. Para Silva, é nesse aspecto que Brandão dialoga com um espírito ateísta materialista.

O segundo nome destacado por Silva, é Caio Prado Júnior (1907-1990), historiador, filósofo e também membro do PCB, desde 1931. Silva mostra que Caio Prado Jr. é menos conhecido por suas questões filosóficas, e mais por seus trabalhos como historiador. A principal obra destacada por Silva é Dialética do conhecimento (1952), obra em que Prado Jr. coloca, em suma, o método dialético como suficiente para dar conta de explicar o mundo e sua realidade movimento de tese, antítese e síntese, e em oposição e superação da metafísica. Segundo Silva (2020, p. 138), tanto para Brandão, quanto para Prado Jr., “[...] o materialismo dialético representaria [...] tanto uma epistemologia (teoria do conhecimento) quanto uma ontologia (a essência ou modo de ser da própria realidade).”.

\section{Ciberateísmo e a criação da Revista Ateísta}

Nosso quarto tema diz respeito ao tópico "A criação da Revista Ateísta", entre as páginas 198-218. Aqui Ricardo Oliveira da Silva destaca o ciberateísmo - a atividade militante de ateus através de recursos da Internet (redes sociais, blogs, sites, etc.). A democraticidade da Internet, ou seja, esse espaço virtual aberto onde qualquer um pode deixar sua opinião sobre qualquer coisa e de qualquer forma, tem se tornado o espaço privilegiado para que as minorias se expressem, sobre si mesmos e sobre sua visão de mundo. Não seria diferente para os ateus. O ciberespaço é o principal meio de divulgação das ideias ateístas, principalmente desse neoateísmo do século XXI, em que essa identidade tem se moldado através da rivalidade com os argumentos da religião (geralmente teísta), do problema da laicidade do Estado democrático e do combate aos preconceitos contra ateus. Esse assunto se encontra mais aprofundado no tópico “O fenômeno do ciberateísmo e a Revista Ateísta” (2020, p. 185-198).

Segundo Silva, a Revista Ateísta teve seu primeiro número lançado em 2013, em formato digital, e foi idealizada pelo jornalista Gabriel Filipe. Sua primeira edição impressa 
ocorreu em 2014, através de seu quinto número. Podemos dizer que, essencialmente, a Revista é uma forma de coletar e divulgar estudos, filosofias, concepções de forma organizada diferentemente de uma feira de opiniões esparsas que se dá na Internet. Entretanto, segundo o autor, para Gabriel Filipe (2014, p. 2) apud Silva (2020, p. 199) "Nossas opiniões muitas vezes são contraditórias, mas isso não é de forma alguma negativo, e será através dessa pluralidade de pensamento que vamos conseguir evoluir nossa capacidade cognitiva”.

Após investigação, Silva constatou que a Revista tem por intuito maior mostrar posicionamentos ateístas diante de temas diversos (religiosos, políticos, conceituais, científicos, sociais, educacionais, etc.). A Revista também explora os ideais do neoateísmo, promovendo entrevistas com seus principais expoentes, como Richard Dawkins e Daniel Dennett. As produções da Revista já logram visibilidade tanto nos ciberespaços nacionais quanto internacionais - e como bem mostrou Silva, também nas universidades junto com a organização Atea - no mais, em seu livro, o autor segue apresentando diversos temas explorados e divulgados pela Revista, subdividindo-os em subtópicos (preconceito, identidade, militância, laicidade estatal, ciência, ética, feminismo).

\section{Ateísmo e as mulheres}

Por fim, nosso último tema tem por base a apresentação do subtópico "Ateísmo e feminismo", entre as páginas 215-218, que Ricardo Oliveira da Silva coloca como um dos temas que a Revista Ateísta apresenta em sua sétima edição (2016-17) - feminismo, no sentido de lutar por mais espaço para as mulheres, na sociedade civil. Para isso, o autor seleciona dois artigos de Glorinha Silva (Glória Amâncio da Silva, que preside a Associação Ateísta do Planalto Central - APCE). O primeiro deles é “O ateísmo e as mulheres”. Nele, segundo o autor, Glorinha Silva tem por interesse problematizar a presença feminina no espaço ateísta de discussões. Argumenta, segundo Oliveira da Silva, que as mulheres são o que quiserem ser, inclusive ateias.

Questiona a dualidade social propagada e sustentada por espaços que vivificam a normatividade social, em que homens são socialmente celebrados como racionais, inteligentes, sensatos, criativos e mulheres como naturalmente emotivas, apaixonadas, carentes de atenção, sonhadoras, temperamentais. Segundo Ricardo Oliveira (2020, p. 216), Glorinha Silva exalta nomes de mulheres que romperam barreiras normativas de suas sociedades, "como Hipátia de Alexandria, Rosa Luxemburgo, Marie Curie, Nise da Silveira, Maria Quitéria, Rosa Parks, e Simone de Beauvoir", mulheres que contribuíram para a ciência e para a cultura humana. Para 
ela, há a necessidade de a mulher superar os valores impregnados pelos homens na sociedade, atividade esta que nunca será simples ou fácil.

Além disso, mostra o autor que Glorinha Silva reconhece que existem mais homens ateus do que mulheres ateias, e por isso questiona o lugar social atribuído às mulheres - controle de seus corpos, controle de seus valores; a autora cita um depoimento de Asa Heuser (ateia da LiHS - Liga Humanista Secular do Brasil), que, segundo Ricardo Silva, busca exemplificar que as mulheres, nos moldes teístas de sociedade, sofrem muito mais pressão do que os homens, para se conformarem em cumprir com um papel ou com uma imagem social preestabelecida e passiva de severa repreensão familiar e social, acaso se descumpra ou se questione essa normatividade (do recato em vestir-se, da beleza, do belo corpo, do pouco opinar, do cuidado apenas com o bem-estar do marido e dos filhos, da vida sexual restringida, da manutenção da moralidade social e da religião no lar, etc.). Esses fatores dificultam o acesso das mulheres ao conhecimento lato de mundo, da possibilidade de ascender socialmente e de lograr uma vida de independência de ações e de livre pensamento.

Essa questão da liberdade das mulheres é destacada por Glorinha Silva, segundo Ricardo Oliveira, ao também mencionar o depoimento de Patrícia Theunissen (residente na Nova Zelândia), que compreende o ateísmo como uma via de liberdade feminina. Liberdade, para Glorinha, é o próprio direito de ir e vir, de se mostrar como ateia, de não depender de homens, ou de instituições religiosas e de seus deuses.

Por fim, o autor destaca o segundo artigo de Glorinha Silva, "As mulheres e a ciência", publicado na oitava edição da Revista (2017-18). Segundo a autora, mostra Silva, interesses sociais teístas, por muitos séculos, impossibilitaram a presença feminina na ciência. A participação da mulher na sociedade teísta foi minada. A autora conjectura, de acordo com Ricardo Silva, a participação das mulheres na vida social das tribos pré-históricas, argumentando que não haveria sociedade se o papel caçador e coletor delas fosse negado, além da arte de lidar com a natureza para se produzir remédios. Desde os tempos mais remotos, além de mães, mulheres foram cientistas, médicas, professoras, poetas, filósofas, chefes, escritoras, etc. e muitas delas mudaram a rota da história humana para melhor, mesmo anônimas. Nesse artigo, mostra Silva, Glorinha retoma nomes como Hipátia de Alexandria (século IV-V E.C.) professora, astrônoma, filósofa, matemática) -, Marie Curie (1867-1934) - química, descobridora dos compostos polônio e rádio -, e Nise da Silveira (1905-1999) - médica, psiquiatra, que combateu o método da lobotomia e terapias de choque. 
Segundo o autor (2020, p. 218), para Glorinha Silva, as mulheres precisam de igual incentivo à ciência na educação básica, contudo, reconhece que em países mais teístas lhes são impostas obrigações familiares, e, ao lograr emprego, tende a ser remunerada com valores mais baixos do que os dos homens em uma mesma função. Assim, "Nesse sentido, criar mecanismos de inserção das mulheres no mundo da ciência seria mais uma forma de lutar pela igualdade de gênero", no Brasil e no mundo.

\section{Considerações Finais}

A partir da apresentação desses tópicos, podemos propor alguns comentários e considerações finais, ou parciais, sobre esse estudo do ateísmo no Brasil.

Em Ateísmo: definições, podemos notar que certos autores, que se debruçam sobre o estudo do ateísmo, tentam elaborar fórmulas, definições, tentam construir alguma rota conceitual mais sólida sobre a questão. Como Silva diz, é um anseio mais normativo do estudo. Ou seja, perguntar “o que é ateísmo?”, “o que é ser ateu?”, funcionam aí como input para fórmulas definidoras. Supõe-se, desse anseio, que ateísmo seja uma forma de pensar o mundo, uma forma plural, mas que não vê com bons olhos a perspectiva de mundo com seres divinos, oriundo de dogmas teístas ou de religiões bíblicas. Decerto que aquilo que mais está em jogo nessas definições é uma disputa ideológica e política acerca da valia de uma sociedade autossuficiente sob as rédeas da ciência, uma sociedade laica, ou, em menor escopo, um Estado de fato laico e democrático.

Outrossim, "ser ateu” perpassa também por essa correlação: de alguém que escolhe não tomar partido de questões levantadas por religiões teístas, como: “deus existe?", “Jesus é deus?", "virgindade de Maria", "santos existem?", "ser justo e bom é ser crente em deus/Jesus", ou de alguém que toma partido de tais questões e entra em disputa ou conflito argumentativo com elas. Vale a pena lembrar que, da mesma forma que alguém ou algum grupo pode se apresentar voluntariamente como "ateu”, uma pessoa ou grupo pode ser igualmente alcunhado de "ateu/ateia", sem o seu consentimento, ou seja, como uma forma de acusação (pejorativa ou não). Esses embates demonstram a complexidade do tema, que, como mostra Silva, ainda está engatinhando em âmbito nacional.

Em Historiografia brasileira e o ateísmo, aproveitamos essa retomada para destacar, outra vez, nomes de autores que comumente aparecem como expoentes desse pensamento ateísta contemporâneo: Auguste Comte, Charles Darwin e Herbert Spencer (ateísmo 
cientificista); Ludwig Feuerbach, Karl Marx, Friedrich Nietzsche e Sigmund Freud (ateísmo humanista); e Richard Dawkins, Sam Harris, Daniel Dennett e Christopher Hitchens (neoateísmo). Como vimos, pela obra de Silva, muitos autores defendem essa longa duração do ateísmo na história e na historiografia, desde os tempos da Grécia Antiga, de onde se abstrai a etimologia da palavra e seus primeiros usos, até essa estruturação mais evidente de noções e visões de mundo ateísta nos séculos XVIII e XIX. Esse cenário é evidentemente europeu. No caso do Brasil, essa discussão entra timidamente no século XX. Esse ateísmo entra no Brasil de forma muito mais ideológica e intelectual, conceitual, nas expressões de adeptos do comunismo. Todavia, será particularmente no século XXI que o ateísmo de fato chega aos cidadãos como um todo, por meio, principalmente, dos ciberespaços (sites, blogs, vlogs, redes sociais) e da militância neoateísta. Vale a pena ressaltar que, em nosso país, o problema do ateísmo não deixa de ser semelhante ao problema da escravidão, no sentido de que muito preconceito e desconhecimento sobre ambos os temas ainda se sustentam no cotidiano do cidadão, o que ocasiona cenários lamentáveis e trágicos de violência verbal e física.

Contudo, essa presença e crescimento recente do ateísmo no Brasil, motivou pesquisas nas universidades, mesmo que ainda poucas, como mostra Silva. Mas, esse interesse investigativo ainda é maior em áreas como ciências da religião, teologia e filosofia. Como mostra Silva, é um estudo da "não religião", da "ausência de religião", de uma visão de mundo "sem deus", ou seja, tema ainda vinculado a questões de estudos filosóficos e teológicos. Entretanto, na área de história, antropologia, sociologia, o autor pôde encontrar trabalhos que adentram em questões mais políticas, de militância de grupos (como da ONG Atea), de disputas ideológicas, temas mais jurídicos, constitucionais, da laicidade do Estado democrático, do combate ao preconceito contra ateus e ateias no país - que mostra claramente a complexidade do tema ainda por ser mais e mais explorado academicamente.

Em Intelectuais comunistas no Brasil, vimos como esses intelectuais adeptos do comunismo foram pioneiros na discussão que remete ao ateísmo no Brasil, seja em âmbito filosófico, seja em âmbito político - também vale a pena mencionar o periódico anarquista $A$ Lanterna (1901-1935) e a oposição ao clero brasileiro. Através da obra de Silva, observamos que essa primeira tomada ateísta tem suas bases no materialismo histórico e dialético das obras de Marx e Engels - assim chamado "ateísmo materialista", "ateísmo marxista" ou "ateísmo humanista". O destaque do tema ficou sob dois autores: Octávio Brandão e Caio Prado Júnior - ambos membros do PCB, fundado no início do século XX. No mais, as bases desse ateísmo oriundo do pensamento marxista (e marxista-leninista) seriam: a valorização do ser humano, da 
criatividade humana, da natureza e dos seus constantes ciclos, da biologia dos seres, da ciência e da tecnologia, da materialidade, do método dialético, e claramente a desvalorização do sistema de interesses que favorece os opressores da sociedade. Podemos dizer que, essa expressão ateísta do século XX ainda não foi tão explícita ou evidente, se compararmos com a do ativismo neoateísta do início do século XXI, uma vez que, em boa parte desse século XX, ateus estavam sob vigilância de regimes totalitários e autoritários conservadores, nos quais muitos foram exilados, presos e silenciados.

Em Ciberateísmo e a criação da Revista Ateísta, vemos como ateus e ateias têm encontrado, na Internet, espaço privilegiado de voz. Não só ateístas, mas religiões de matriz africana, judeus, islamitas, filosofias asiáticas e indígenas, no geral, minorias cuja episteme foi silenciada, negada ou combatida por séculos, na história cristã do Brasil. Todas, em comum, se expressam sob o direito de liberdade democrática e laica do Estado. Contudo é particularmente nesse âmbito do ciberespaço que essa liberdade se faz mais real, mais efetiva. Esse é um dos principais temas e questionamentos da Revista Ateísta. Afinal, como é esse Estado laico brasileiro? Por que só feriados cristãos são civis e interferem no serviço público? Seria o Estado brasileiro laico, ou cristão católico, que admite a presença de outras manifestações religiosas, mas sem privilegiá-las no âmbito civil? Como a lei trata dessas questões? Aliás, como o brasileiro reage ao ouvir termos como "laico" e "secular"? O que o brasileiro pensa sobre "ateísmo"? Essas questões movem o interesse do tema do ateísmo no Brasil, e estão além do tema da "não religião", ou dessa rivalidade "ciência versus religião"; são questões sociopolíticas, legislativas, de direitos e deveres do Estado e do cidadão diante de uma constituição democrática.

Em Ateísmo e as mulheres, aproveitamos o ensejo de Ricardo Silva, em explorar esse tema em seu livro, para dar espaço à questão da mulher na sociedade civil democrática. $\mathrm{O}$ autor toma por base os argumentos de Glorinha Silva (voz da APCE) sobre as relações: mulher, ateísmo e ciência na história, por meio de dois artigos. No geral, podemos notar que, de fato, a realidade feminina tem sido cerceada de diversas formas ao longo da história humana, principalmente, em nosso caso, em sociedades teístas (cristianismos, judaísmos, islamismos). O tópico mostra como mulheres têm participado da vida social desde os tempos remotos, préhistóricos, onde se pressupõe sua maior atuação, e depois, com a ascensão de formas de governo imperialistas, ou seja, baseadas numa monarquia, no exército, na defesa e na expansão de territórios, essa historiografia se mostrou mais masculina, e nela a voz da mulher será quase 
sempre intermediada pela voz do homem, ou seja, o homem diz ou registra a voz da mulher, ou, de uma personagem feminina.

Nisso, se construiu o lugar da mulher pelo discurso do homem: do lar, da cozinha, da família, da educação básica, do serviço sexual (fertilidade), da manutenção da cultura, da malícia, da adivinhação, da bruxaria, da feitiçaria, da sensibilidade ao sobrenatural, convocada às armas somente em casos extremos, e também do não lugar da mulher: no campo de batalha, no estudo avançado (escrita, leitura, ciências, artes), na política, nas decisões da sociedade como um todo. Atualmente, alguns países já superaram grande parte desses preconceitos contra o feminino, e a maioria deles são países laicos, onde a religião não participa das decisões civis e a população em boa parte é secular (não necessariamente ateia). Em contrapartida, é para formas teístas de sociedade que Glorinha, segundo compreendemos de Silva, dirige as suas críticas, nesse mundo contemporâneo, em particular, ao Brasil. E é nesse sentido que a autora promove a luta pelo incentivo familiar e escolar às ciências, não só para meninos, mas igualmente para meninas, pois, para ela, subentende-se, nada justifica a exclusão delas dessas esferas da vida social, pública, do trabalho, da educação e, por que não, de também poder se declarar ateia, sem repressão moral e preconceito.

A obra de Ricardo Oliveira da Silva vem para ajudar a preencher com maestria uma lacuna que de fato está exposta em nossa historiografia e nos interesses de pesquisas acadêmicas, principalmente na área de humanas. Nosso empenho particular pelo tema do ateísmo e sua história nos motivou a buscar por trabalhos relacionados - e que já nos rendeu uma dissertação defendida em 2019, intitulada “Ateísmo na Antiguidade: aspectos teóricos e metodológicos para a inserção do tema na Antiguidade Egípcia, Mesopotâmica e IsraeloJudaíta e pressupostos para o estudo na Antiguidade Clássica", junto ao PPG em Letras Clássicas da UFRJ. Conhecemos a obra de Ricardo Oliveira em pesquisa na Internet, através de divulgação feita pelo próprio autor em seu canal no YouTube chamado Ricardo Russell, canal onde o autor divulga seus trabalhos e apresenta diversas obras e conteúdos sobre a temática, além de realizar entrevistas com adeptos do ateísmo, sejam cidadãos comuns ou membros de grupos organizados, como Glorinha Silva. No mais, entendemos que essa é uma obra recomendada para todos os cidadãos que se preocupam com os usos e abusos da democracia por parte de políticos e governantes, não apenas para aqueles interessados na história do ateísmo, ou na sua particularidade no Brasil. A obra vai além do estudo da historiografia, pois entra no campo da cidadania para trazer aparato crítico aos leitores, para 
que conheçam a história de seu próprio país a partir de olhares e vozes comumente localizados à margem do sistema.

\section{REFERÊNCIAS}

BAGGINI, J. Ateísmo: uma breve introdução. Porto Alegre: L\&PM, 2016.

BRANDÃO, O. O primado da natureza - ciência e filosofia. Revista Brasiliense, São Paulo, n. 37, p. 115-128, 1961.

CLITEUR, P. The Definition of Atheism. Journal of Religion and Society, v. 11, p. 1-23, 2009.

LEDREW, S. Scientism, Humanism, and Religion: the New Atheism and the Rise of Secular Movement. 2013. 249f. Dissertation (Doctor of Philosophy) - York University, Toronto, 2013.

MARTIN, M. (org.). Um mundo sem Deus: Ensaios sobre ateísmo. Lisboa: Edições 70, 2010.

MINOIS, G. História do ateísmo: os descrentes no mundo ocidental, das origens aos nossos dias. São Paulo: Editora Unesp, 2014.

PRADO JÚNIOR, C. Dialética do conhecimento. São Paulo: Ed. Brasiliense, 1952 (dois tomos).

REVISTA ATEÍSTA. A difícil tarefa de ser ateu no Brasil. Revista Ateísta, s/1., n. 5, p. 22-25, 2014. (Matéria de capa).

SILVA, G. As mulheres e a ciência. Revista Ateísta, s/l., n. 8, p. 24-25, 2018. O ateísmo e as mulheres. Revista Ateísta, s/l., n. 7, p. 26-27, 2016.

SILVA, Ricardo Oliveira da. O ateísmo no Brasil: os sentidos da descrença nos séculos XX e XXI. Jundiaí, SP: Paco Editorial, 2020.

THROWER, J. Breve história do ateísmo ocidental. Lisboa: Edições 70, 1971. 